\title{
Fall-Related Injuries in Community-Dwelling Older Adults in Qom Province, Iran, 2010-2012
}

\author{
Hamid Reza Gilasi ${ }^{1}$; Hamid Soori ${ }^{2,}$; Shahram Yazdani ${ }^{3}$; Parisa Taheri Tenjani ${ }^{4}$ \\ ${ }_{1}^{1}$ Department of Epidemiology, Shahid Beheshti University of Medical Sciences, Tehran, IR Iran \\ ${ }^{2}$ Safety Promotion and Injury Prevention Research Center, Shahid Beheshti University of Medical Sciences, Tehran, IR Iran \\ 3 Faculty of Medical Education, Shahid Beheshti University of Medical Sciences, Tehran, IR Iran \\ ${ }^{4}$ Department of Internal Medicine, Ayatollah Taleghani Hospital, Shahid Beheshti University of Medical Sciences, Tehran, IR Iran \\ ${ }^{*}$ Corresponding author: Hamid Soori, Safety Promotion and Injury Prevention Research Center, Shahid Beheshti University of Medical Sciences, Tehran, IR Iran. Tel: +98-9133611401, \\ Fax: +98-2122439980, E-mail: hsoori@yahoo.com
}

Received: August 19, 2014; Revised: November 14, 2014; Accepted: December 10, 2014

\begin{abstract}
Background: Falls and related injuries are common health problems in the elderly. Fractures, brain and internal organ injuries and death are the common consequences of the falls, which result in dependence, decreased self-efficacy, fear of falling, depression, restricted daily activities, hospitalization and admission to the nursing home and impose costs on the individual and the society.

Objectives: The purpose of this study was to determine the types of fall-related injuries and the related riskfactors in the elderly population of Qom province, Iran.

Patients and Methods: This retrospective study was performed on 424 elderly people (65 years and over) referred to Shahid Beheshti Hospital, Qom, Iran, due to falls between 2010 and 2012. The ICD-10 codes of external causes of injury from w00 to w19 related to falls were selected from the health information system of the hospital and demographic variables of the patients and external causes of falls were extracted after accessing the files of the patients. Data were analyzed using SPSS version 18 (SPSS Inc., USA). The duration of hospital stay and its relationship with underlying variables were investigated using t test and ANOVA. The level of significance was considered $\mathrm{P}<0.05$. Results: Among 424 elderly people, 180 cases $(42.45 \%)$ were male and the mean age of the patients was $78.65 \pm 7.70$ years. Fall on the same level from slipping, tripping, and stumbling was the most common external cause with 291 victims (68.60\%), and hip fracture in 121 patients (29.00\%), intertrochanteric fracture in 112 patients (26.90\%), and traumatic brain injury in 51 patients $(12.20 \%)$ were the most common causes of hospital stay. The mean hospital stay was $7.33 \pm 3.63$ days.

Conclusions: Lower limb fracture and traumatic brain injury were the most common causes of hospitalization, which resulted in the longest hospital stay and highest hospitalization costs in the elderly.
\end{abstract}

Keywords:Elderly; Hospitalization; Injury; Length of Stay

\section{Background}

Falls and related injuries are one of the health problems of the elderly and communities with an elderly population (1). The frequency of falls is higher in the elderly, women, individuals with a previous history of falling, and the residents of nursing homes (2). Population and disease control programs and improved education have increased life expectancy and the percentage of the elderly in different societies (3). Falls occur in about $35-40 \%$ of the elderly during one year and about half of them experience repeated falls. In the US, accidents are the fifth common cause of elderly mortality and falls are the most common cause of trauma in this age group (4).

A fall can have lethal and non-lethal consequences. About $11 \%$ of the older people die following the falls (5). The mortality trend of the falls increased by up to $59 \%$ in the US, Finland, and Spain and from 31.8 in 100000 to 46.7 in 100000 in men and from 19.5 in 100000 to 31.1 in 100000 in women from 1993 to 2003 (6-8). About 40-60\% of the falls end in injury. Fracture of the limbs, blow or impact to the skull and brain, fracture of the vertebrae and ribs, and soft tissue and internal organ injury are common consequences, which result in dependence, decreased self-efficacy and fear of falling, restricted daily activities, hospitalization, and admission to the nursing home, and impose costs on the person and the society $(9,10)$. It has been estimated that about $40 \%$ of long hospital stays in the elderly are due to falling (11).

Fractures comprise about $10-20 \%$ of the injuries with hip fracture being the most frequent. Half of the elderly population with hip fracture cannot return to normal life and experience levels of disability and about $20 \%$ of them die during one year. Head trauma and fractures of the upper limbs are other serious complications of falling $(12,13)$. It has been estimated that one third of the costs of accidents are related to falls and two thirds of the direct costs are related to hospitalization. It has been predicted that the number and costs of fall-related injuries will increase by three times and the rate of hospitalization due to falls will

Copyright (c) 2015, Kashan University of Medical Sciences. This is an open-access article distributed under the terms of the Creative Commons Attribution-NonCommercial 4.0 International License (http://creativecommons.org/licenses/by-nc/4.0/) which permits copy and redistribute the material just in noncommercial usages, provided the original work is properly cited. 
increase by 10 times by $2050(14,15)$.

Many risk factors are associated with falling, which are categorized as internal or environmental factors or personal, nutritional, economic, social, drug, and medical status causes. Low light of the environment, unsafe stairs, slippery rug, improper shoes, concomitant use of several drugs, use of hallucinogens, musculoskeletal weakness, balance and gait disorders, visual impairment, nutritional problems like calcium and vitamin D insufficiency, and cardiovascular disease are more common risk factors of falls in the elderly $(4,16,17)$. The increase in the number and percentage of the elderly in modern societies, rapid growth of the elderly population in Iran, differences in the risk factors for falls in different societies, the high incidence of falls in the elderly and high expenses of falls and fall-related injuries in the elderly show the necessity of conducting studies in this regard.

\section{Objectives}

Considering the lack of adequate and accurate information in Iran, the present study was conducted to determine the types of fall-injuries and their related risk factors in the elderly population of Qom Province, Iran. The results of this study can be useful in advance care planning for the elderly.

\section{Patients and Methods}

In this retrospective study, hospital files of all individuals (65 years and over) who were hospitalized at Qom Shahid-Beheshti Hospital due to falls between 2010 and 2012 were reviewed. This hospital is the major trauma center in Qom. The external cause codes of w00-w19 based on ICD10 related to falls were selected from the health information system of the hospital (HIS) and the data from 2010 to 2012 were extracted. Inclusion criteria were the age of 65 and older and the occurrence of falls between 2010 and 2012. After organizing the primary data based on the patients' age, all patients who were at least 65 years old were selected and their files were accessed through their hospitalization codes. The external causes and the patients' age were rechecked against their files and missing data were completed. In addition to age and the external causes of falls, the variables of sex, hospitalization date, discharge date, duration of hospital stay, final diagnosis, surgery and its code, and death and its cause(s) were extracted from the patients' files by an experienced medical document expert. The collected data were entered into SPSS software for statistical analysis. Mean and standard deviation were estimated for quantitative variables and frequency was calculated for qualitative variables. In addition to providing a description of the patients, the duration of hospitalization for different diagnostic codes was investigated and the relationship between the duration of hospitalization and underlying variables was also evaluated using the independent sample t test, ANOVA or their non-parametric equivalents (Mann Whitney U and Kruskal Wallis). The level of significance was set at $\mathrm{P}<0.05$.

\section{Results}

Of all the patients, 180 (42.45\%) were male. The mean age of the patients was $78.65 \pm 7.70$ years with a median of 79 years (range, 65-109 years old). Most of the falls (36.6\%) occurred in 2012. Table 1 shows the distribution of different age groups based on the year of hospitalization. In the three years of the study, the age groups 75-84 and 85 and older had the highest and lowest proportion, respectively. The time distribution of the falls did not differ among months and seasons and $24.80 \%, 26.40 \%, 24.30 \%$, and $24.50 \%$ of the patients were hospitalized in the spring, summer, autumn, and winter, respectively.

Table 1. Distribution of the Age of the Elderly Hospitalized Due to Falls Based on the Year of Hospitalization ${ }^{\text {a }}$

\begin{tabular}{ccccc}
\hline Variable & $\mathbf{2 0 1 0}$ & $\mathbf{2 0 1 1}$ & $\mathbf{2 0 1 2}$ & Total \\
\hline Ages, $\mathbf{y}$ & & & & \\
$65-74$ & $31.3(45)$ & $35(28)$ & $57(36.8)$ & $137(32.3)$ \\
$75-84$ & $61(42.2)$ & $59(47.2)$ & $57(36.8)$ & $177(41.7)$ \\
$>85$ & $39(26.4)$ & $31(24.8)$ & $41(26.5)$ & $110(25.9)$ \\
\multicolumn{7}{l}{ Total } & $144(100)$ & $125(100)$ & $155(100)$ & $424(100)$ \\
\hline \multicolumn{7}{l}{ a Data are presented as No.(\%). }
\end{tabular}

Table 2. Mean Hospital Stay Due to Falls in the Evaluated Elderly Population ${ }^{\text {a }}$

\begin{tabular}{lll}
\hline Injuries or Fractures & Patient, No. & $\begin{array}{l}\text { Length of } \\
\text { Stay, d }\end{array}$ \\
\hline Hip & 121 & $0.66 \pm 7.60$ \\
\hline Intertrochanteric & 112 & $8.14 \pm 0.27$ \\
\hline Shaft of femur & 7 & $1.05 \pm 7.58$ \\
\hline Distal of femur & 14 & $5.50 \pm 9.24$ \\
\hline Pelvis and acetabulum & 29 & $3.87 \pm 6.03$ \\
Tibia, fibula and patella & 8 & $3.00 \pm 4.80$ \\
\hline Head trauma & 51 & $6.80 \pm 9.00$ \\
Vertebra & 28 & $2.60 \pm 5.50$ \\
Ribs & 8 & $2.95 \pm 2.00$ \\
\hline Humorous and clavicle & 7 & $1.80 \pm 2.70$ \\
\hline Radius, Ulna and metacarpus & 17 & $4.00 \pm 4.60$ \\
\hline Strain, sprain and dislocation & 6 & $0.55 \pm 1.50$ \\
\hline Unknown & 16 & $3.00 \pm 5.20$ \\
Total & 424 & $3.63 \pm 7.33$ \\
\hline a
\end{tabular}

${ }^{\mathrm{a}}$ Data are presented as mean \pm SD.

Table 3. Distribution of the Death of the Elderly Hospitalized Due to Falls Based on the Age, Sex, and Surgery ${ }^{\text {a }}$

\begin{tabular}{llll}
\hline Variables & Alive & Death & P Value \\
\hline Gender & & & 0.49 \\
$\quad$ Male & $161(89.4)$ & $19(10.6)$ & \\
Female & $223(91.4)$ & $21(8.6)$ & \\
Age Group, yr & & & 0.17 \\
$65-74$ & $129(94.2)$ & $98(5.8)$ & \\
$75-84$ & $159(89.8)$ & $18(10.2)$ & \\
$\geq 85$ & $96(87.3)$ & $14(12.7)$ & \\
Surgery & & & 0.26 \\
No surgery & $140(92.7)$ & $11(7.3)$ & \\
Surgery & $244(89.4)$ & $29(10.6)$ & \\
\hline a Data are presented as No.(\%). &
\end{tabular}

\footnotetext{
$\mathrm{a}$ Data are presented as No. (\%).
} 
A total of 404 elderly people (95.50\%) had medical insurance policies, including Medical Services Insurance (40.10\%), Social Security Insurance (40.10\%), Imam Khomeini Relief Foundation Insurance (10.40\%), Armed Forces Insurance (7.50\%) and other insurances (2.60\%). The external causes of falls were fall on the same level from slipping, tripping and stumbling in 291 people (68.63\%), fall from height in 88 people $(20.76 \%)$, fall on and from stairs and steps in 33 people (7.78\%), fall involving bed in 8 people $(1.89 \%)$ and other causes in 4 people $(0.94 \%)$.

Regarding the final diagnosis documented in the patient file, the most frequent injuries were hip fracture ( $\mathrm{n}$ $=121,28.54 \%)$, intertrochanteric fracture $(n=112,26.42 \%)$, and head trauma, skull fracture, and brain hemorrhage $(n=51,12.03 \%)$. Figure 1 shows the distribution of final diagnosis in the hospitalized elderly. According to Figure 1, fracture of the lower limbs (62.80\%) was the most common injury. Surgery was performed on 273 hospitalized persons (64.39\%) and the remaining 151 elderly people (35.5\%) received medical treatment. Of 51 cases of head trauma and injury, 29 cases (57\%) underwent surgery.

The total hospital stay was 3108 days, the mean hospital stay was $7.33 \pm 3.63$ days, and the median hospital stay was 6 days, ranging from 1 day to 44 days (95\% CI: 6.98-7.68). The mean hospital stay was $7.9 \pm 7.5$ days in men and $6.8 \pm$ 6.17 days in women with no significant difference. Moreover, the mean hospital stay was a little longer in older patients; however, the difference was not significant. Hospital stay was significantly longer in patients who received surgery and died when compared to the patients who did not undergo surgery and recovered $(\mathrm{P}<0.001)$. Table 2 shows the mean and standard deviation of the hospital stay for each diagnosis. According to Table 2, the mean hospital stay was the longest in cases with distal femur fracture and skull injuries and was the shortest in cases with sprain, strain, and dislocation.
A total of 40 elderly persons (9.4\%) who were hospitalized due to falls died in the hospital, which comprised 20 main causes of death all together. The most common causes of death in the hospitalized patients were circulation and blood problems (35\%), neurologic problems (30\%), and respiratory problems (25\%). The death rate was $10.6 \%$ in men, $8.6 \%$ in women, $10.6 \%$ in surgical cases, $7.3 \%$ in nonsurgical cases, $5.8 \%$ in the younger elderly (65-74 years old), and $12.7 \%$ in the older elderly ( $\geq 85$ years old). The association between age, sex, surgery and death was not statistically significant (Table 3 ).

\section{Discussion}

The present paper exclusively evaluated hospitalization due to falls in the elderly. Although this study does not represent the whole Iranian population, it provides valuable information on the injuries. In our study, $57.5 \%$ of the elderly who were hospitalized due to falls were women, which is in line with the results of the studies by Zamani, Alamgir, Orces, Pfortmueller and Skalska and their colleagues (18-22). Osteoporosis due to hormonal changes is common in menopausal women, which can result in fracture and hospitalization (23).

The mean age of the hospitalized elderly in our study was 78.65 years and $44.6 \%$ of the elderly were in the age group 75-84 years. The age group 85 years and over comprised the lowest number of hospitalized elderly. Studies performed by Mould-Quevedo, Skalska and Ungar have reported more hospitalization in the age group 75-84 years, which is congruent with our findings $(15,22,24)$. Since the number of older people in the age group 85 years and over in the society is less than other elderly groups, despite the direct relationship between age and falls, fewer hospitalized elderly persons belonged to this age group.

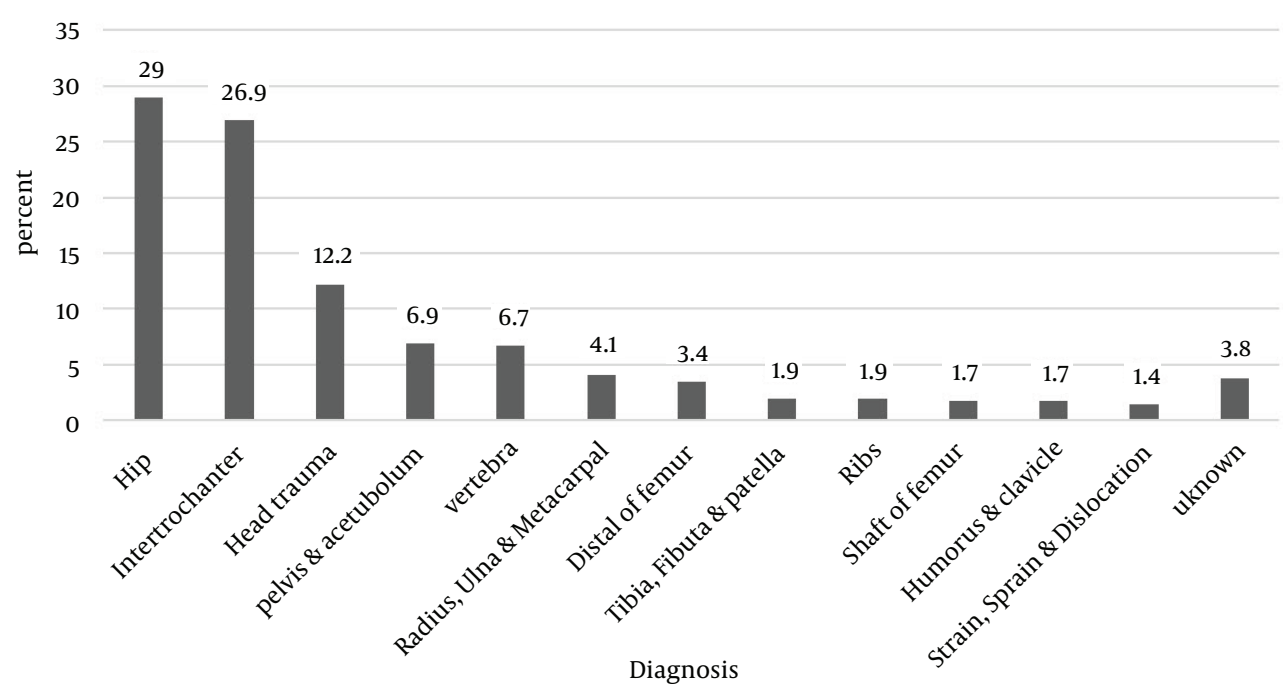

Figure 1. Frequency Distribution of Different Final Diagnoses in the Elderly Population Hospitalized Due to Falls 
In a study by Li et al. hospital admission due to falls in the active elderly was 6 times more than the old and disabled elderly. Moreover, the prevalence of musculoskeletal, balance, and visual disorders and other chronic diseases is related to age, which makes them more prone to falls and fall-related injuries (25). The fewer number of older people in the age group 85 years and over, their inactivity, more support of the family, and more admission to institutes and nursing homes may be the reason for less hospitalization in this age group $(26,27)$.

The most common external causes of falls were fall on the same level (68.8\%) followed by fall from height and fall on and from stairs. Fall on the same level was reported in $55 \%$ of the patients by Adam (28) and in $68 \%$ of the patients by Ghodsi (29), which is similar to the results of the studies performed by Skalska (22), Mitchell (30), Salarvand (31) and Harvey (32). Many studies have reported balance disorders, visual and gait problems, orthostatic hypotension, and slipperiness of the surrounding area of the house as risk factors for falls in the elderly, which mostly result in fall on the same level $(2,16,17,33,34)$.

Injuries of the lower limbs, especially the femoral neck and intertrochanteric fracture, were the most common among the hospitalized elderly (35) followed by skull and brain injuries (12.2\%) and injuries of the upper limbs. According to some studies, fractures of the upper limbs, vertebrae, hip, and head trauma closely follow hip fracture, which is similar to our results $(29,36,37)$. Adam reported that fractures of the lower limbs were the most common and brain damage was detected in $9 \%$ of the patients who fell on the same level (28). Falls are the second cause of brain and spinal injury in the elderly (38).

Among different types of brain injury, subdural and subarachnoid hemorrhage and hematoma were more common in our study. In a review study, Harvey et al. evaluated brain injury following accidents in the elderly in 2012 and reported that subdural and subarachnoid hematoma were the most common brain injuries and falls were the most common cause of accidents (82.9\%), which is similar to our findings (32). In a study in Italy, Iaria found that head trauma together with thorax trauma were the most common injuries in accidents (39). The difference between the findings of this study and our study could have resulted from the evaluation of traffic accidents, which increases the frequency of head trauma. In most extensive studies, fractures of the lower limbs are in the first diagnostic rank. The difference in the second rank in patients hospitalized in different hospitals is related to the referral bias (40).

The mean hospital stay was 7.33 days in our study, 7.63 days in a study by Nader (36), 7.23 days in a study by Soltani (41), 7.99 days in a study by Zamani (18), 16.3 days in head trauma patients in a study by Abasi Moghadam (42), 9 days in a study by Vu (43), and 4-15 days in a study by Das (44). The mean hospital stay was longer in patients with head trauma in our study, as well. In our study, there was a significant positive correlation between the duration of hospital stay and age, mortality, and surgery, which was in line with the results of studies conducted by Zamani, Nader, Soltani and Abasi Moghadam $(18,36,41,42)$. In general, hospital stay is longer in the elderly patients when compared to other age groups and depends on the type of disease, concomitant diseases, and type of intervention. Watson reported that hospital admission rate due to falls increased by $1.7 \%$ annually from 1999 to 2009 in Australia and predicted that the rate would increase by 10 times by 2050. Considering the trend of population aging in many countries, the trend of falls and fall-related injuries and hospitalization will be increasing in most countries (45).

In our study, 40 persons (9.4\%) died. Other studies have also reported death due to falls or due to accidents in general. Nader et al. reported death in $6.28 \%$ and $2.5 \%$ of the people who were hospitalized due to accidents and falls, respectively (36). Death was reported in $17.2 \%$ of the patients with femur fracture in a study by Zamani (18), in $11 \%$ of falls and $25 \%$ of falls from height in a study by Aschkenasy (46), in $6 \%$ of falls in a study by Siracuse (47), and $13 \%$ in head trauma patients in a study by Harvey (32). The deaths reported in our study were short-term deaths in the hospital, which were affected by the type and severity of the accident, hospital admission rate, and specialties available in the hospital. The rate of fall-related deaths would have increased if we had included deaths before referral to the hospital or deaths related to falls and their complications after discharge (48). Numerous studies have identified falls as the most common cause of death due to accidents in the elderly $(6,8,49)$. Wendelboe reported a fall- related mortality rate of 5.6 in 100000 in the US and 11.7 in 100000 in New Mexico in 2005 while in 2012 (6), Alamgir reported a fall-related mortality rate of 36.8 in 100000 in 2003 to 44.9 in 100000 in 2007 with a $22 \%$ increase (19).

In our study, death rate was higher among men than women; however, this difference was not statistically significant. Ghodsi (29) and a study conducted in Finland reported similar findings (8), while Alamgir found that the mortality rates were significantly higher in women than in men (19). The reason for the lack of significant difference in death in our study could be its less power due to low number of deaths. In our study, the mortality rate was higher in older age groups. More concomitant diseases and general weakness of the older elderly result in a higher mortality rate. The relationship between age and fall-related death has been reported in other studies, as well $(25,30,50)$.

According to the results of our study, the most common causes of hospitalization in the elderly victims of falls were femur neck fracture, intertrochanteric fracture and head trauma. The longest hospital stay was seen in distal femur fractures and brain injuries. About 9\% of the hospitalized patients died. Execution of effective fallprevention programs in the elderly can reduce the load of fall-related injuries, improve health in this age group 
and reduce the costs.

\section{Acknowledgements}

The authors wish to thank the faculty members of the Department of Epidemiology and staff of the Medical Documents Ward, especially Mrs. Samira Safari.

\section{Authors' Contributions}

Hamidreza Gilasi was the principal investigator and also participated in drafting of the manuscript. Hamid Soori also contributed to the research equally. Parisa Taheri Tenjani and Shahram Yazdani contributed to the compiling of the data.

\section{Funding/Support}

This study was part of a thesis conducted in Shahid Beheshti University of Medical Sciences with the cooperation of the Department of Epidemiology of Shahid Beheshti University of Medical Sciences and Medical Document Center of Qom Shahid-Beheshti Hospital. This project was funded by Shahid Beheshti University of Medical Sciences.

\section{References}

1. Halter J, Ouslander J, Tinetti M, Studenski S, High K, Asthana S. Hazzard's Geriatric Medicine and Gerontology. 6 ed: McGraw-Hill Education; 2009.

2. Zhou BY, Shi J, Yu PL. [Consequence and risk factors of falls-related injuries in community-dwelling elderly in Beijing]. Zhonghua Liu Xing Bing Xue Za Zhi. 2013;34(8):778-81.

3. Galor O. The Demographic Transition: Causes and Consequences. Cliometrica (Berl). 2012;6(1):1-28

4. World Health Organization.. Global Report on Falls Prevention in Older Age.Geneva: WHO; 2007.

5. Gilbert R, Todd C, May M, Yardley L, Ben-Shlomo Y. Socio-demographic factors predict the likelihood of not returning home after hospital admission following a fall. J Public Health (Oxf). 2010;32(1):117-24.

6. Wendelboe AM, Landen MG. Increased fall-related mortality rates in New Mexico, 1999-2005. Public Health Rep. 2011;126(6):861-7.

7. Hu G, Baker SP. Trends in unintentional injury deaths, U.S., 19992005: age, gender, and racial/ethnic differences. Am J Prev Med. 2009;37(3):188-94.

8. Korhonen N, Kannus P, Niemi S, Palvanen M, Parkkari J. Fall-induced deaths among older adults: nationwide statistics in Finland between 1971 and 2009 and prediction for the future. Injury. 2013;44(6):867-71.

9. Gill TM, Murphy TE, Gahbauer EA, Allore HG. Association of injurious falls with disability outcomes and nursing home admissions in community-living older persons. Am J Epidemiol. 2013;178(3):418-25.

10. Bonne S, Schuerer DJ. Trauma in the older adult: epidemiology and evolving geriatric trauma principles. Clin Geriatr Med. 2013;29(1):137-50

11. Limpawattana P, Sutra S, Thavompitak Y, Chindaprasirt J, Mairieng P. Geriatric hospitalizations due to fall-related injuries. $J$ Med Assoc Thai. 2012;95 Suppl 7:S235-9.

12. Nilson F, Moniruzzaman S, Andersson R. Fall-related fracture trends among elderly in Sweden--exoring transitions among hospitalized cases. J Safety Res. 2013;45:141-5.

13. Orces $\mathrm{CH}$. Emergency department visits for fall-related fractures among older adults in the USA: a retrospective cross-sectional analysis of the National Electronic Injury Surveillance System All Injury Program, 2001-2008. BMJ Open. 2013;3(1)
14. Watson WL, Clapperton AJ, Mitchell RJ. The cost of fall-related injuries among older people in NSW, 2006-07. N S W Public Health Bull. 2011;22(3-4):55-9.

15. Mould-Quevedo JF, Garcia-Pena C, Contreras-Hernandez I, JuarezCedillo T, Espinel-Bermudez C, Morales-Cisneros G, et al. Direct costs associated with the appropriateness of hospital stay in elderly population. BMC Health Serv Res. 2009;9:151.

16. Ambrose AF, Paul G, Hausdorff JM. Risk factors for falls among older adults: a review of the literature. Maturitas. 2013;75(1):51-61.

17. Mitchell RJ, Watson WL, Milat A, Chung AZ, Lord S. Health and lifestyle risk factors for falls in a large population-based sample of older people in Australia. J Safety Res. 2013;45:7-13.

18. Zamani B, Ebadi S, Ahmadvand A, Moosavi G. The Frequency of Osteoporosis in Hip Fracture Following Minor Trauma and The Resulting Mortality Rate And Direct Treatment Costs In Patients Over 45 Years Old In Kashan Naghavi Hospital During 2005-2007. J Kerman Univ Med Sci. 2010;17(2):137-44.

19. Alamgir H, Muazzam S, Nasrullah M. Unintentional falls mortality among elderly in the United States: time for action. Injury. 2012;43(12):2065-71.

20. Orces $\mathrm{CH}$, Alamgir $\mathrm{H}$. Trends in fall-related injuries among older adults treated in emergency departments in the USA. Inj Prev. 2014;20(6):421-3.

21. Pfortmueller CA, Kunz M, Lindner G, Zisakis A, Puig S, Exadaktylos AK. Fall-related emergency department admission: fall environment and settings and related injury patterns in 6357 patients with special emphasis on the elderly. ScientificWorldJournal. 2014;2014:256519.

22. Skalska A, Wizner B, Piotrowicz K, Klich-Raczka A, Klimek E, Mossakowska $\mathrm{M}$, et al. The prevalence of falls and their relation to visual and hearing impairments among a nation-wide cohort of older Poles. Exp Gerontol. 2013;48(2):140-6.

23. Dumitrescu B, van Helden S, ten Broeke R, NieuwenhuijzenKruseman A, Wyers C, Udrea G, et al. Evaluation of patients with a recent clinical fracture and osteoporosis, a multidisciplinary approach. BMC Musculoskelet Disord. 2008;9:109.

24. Ungar A, Rafanelli M, Iacomelli I, Brunetti MA, Ceccofiglio A, Tesi F, et al. Fall prevention in the elderly. Clin Cases Miner Bone Metab. 2013;10(2):91-5.

25. Li YH, Song GX, Yu Y, Zhou de D, Zhang HW. Study on age and education level and their relationship with fall-related injuries in Shanghai, China. Biomed Environ Sci. 2013;26(2):79-86.

26. Vu T, Finch CF, Day L. Patterns of comorbidity in communitydwelling older people hospitalised for fall-related injury: a cluster analysis. BMC Geriatr. 2011;11:45.

27. Sibley KM, Voth J, Munce SE, Straus SE, Jaglal SB. Chronic disease and falls in community-dwelling Canadians over 65 years old: a population-based study exploring associations with number and pattern of chronic conditions. BMC Geriatr. 2014;14:22.

28. Adam SH, Eid HO, Barss P, Lunsjo K, Grivna M, Torab FC, et al. Epidemiology of geriatric trauma in United Arab Emirates. Arch Gerontol Geriatr. 2008;47(3):377-82.

29. Ghodsi SM, Roudsari BS, Abdollahi M, Shadman M. Fall-related injuries in the elderly in Tehran. Injury. 2003;34(11):809-14.

30. Mitchell R, Curtis K, Watson WL, Nau T. Age differences in fallrelated injury hospitalisations and trauma presentations. Australas J Ageing. 2010;29(3):117-25.

31. Salarvand S, Meraci MR, Ghaedi F, Zamani M. Prediction of likelihood of ground falling in hospitalized old patients in Isfahan; by using Morse Fall Scale. Sci J Kurdistan Univ Med Sci. 2010;15(1):63-71.

32. Harvey LA, Close JC. Traumatic brain injury in older adults: characteristics, causes and consequences. Injury. 2012;43(11):1821-6.

33. Pfortmueller CA, Lindner G, Exadaktylos AK. Reducing fall risk in the elderly: risk factors and fall prevention, a systematic review. Minerva Med. 2014;105(4):275-81.

34. Bleijlevens MH, Diederiks JP, Hendriks MR, van Haastregt JC, Crebolder HF, van Eijk JT. Relationship between location and activity in injurious falls: an exploratory study. BMC Geriatr. 2010;10:40.

35. Moayyeri A, Soltani A, Larijani B, Naghavi M, Alaeddini F, Abolhassani F. Epidemiology of hip fracture in Iran: results from the Iranian Multicenter Study on Accidental Injuries. Osteoporos Int. 2006;17(8):1252-7.

36. Nader F, Rakei SM. The epidemiologic aspects of trauma in the 


\section{Gilasi HR et al.}

elderly in Shiraz hospital 1383. Jahrom Med J. 2007;4(4):41-6.

37. Fazel MR, Fakharian E, Razi E, Abedzadeh-Kalahroudi M, Mahdian M, Mohammadzadeh M, et al. Epidemiology of home-related injuries during a six-year period in kashan, iran. Arch Trauma Res. 2012;1(3):118-22.

38. Hartholt KA, Van Lieshout EM, Polinder S, Panneman MJ, Van der Cammen TJ, Patka P. Rapid increase in hospitalizations resulting from fall-related traumatic head injury in older adults in The Netherlands 1986-2008. J Neurotrauma. 2011;28(5):739-44.

39. Iaria M, Surleti S, Famá F, Villari SA, Gioffré-Florio M. Epidemiology and outcome of multiple trauma in the elderly population in a tertiary care hospital in southern Italy. BMC Geriatrics. 2009;9(Suppl1).

40. Etman A, Wijlhuizen GJ, van Heuvelen MJ, Chorus A, HopmanRock M. Falls incidence underestimates the risk of fall-related injuries in older age groups: a comparison with the FARE (Falls risk by Exposure). Age Ageing. 2012;41(2):190-5.

41. Soltani MH. Elderly, duration of hospitalization and Hospital cost in Milad Hospital in Iran. Iran J Ageing. 2012;6(23):58-65.

42. Abasi Moghadam M. Accounting and comparing of expenditure on the medical services given at neuro-surgery department of Imam Khomeyni Hospital in the year of 1994 (1373). Tehran Univ Med J.1998;56(6):82-7.
43. Vu T, Day L, Finch CF. Linked versus unlinked hospital discharge data on hip fractures for estimating incidence and comorbidity profiles. BMC Med Res Methodol. 2012;12:113.

44. Das CP, Joseph S. Falls in elderly. J Indian Med Assoc 2005;103(3):136-138, 140 passim.

45. Watson WL, Li Y, Mitchell RJ. Projections of hospitalised fall-related injury in NSW, Australia: impacts on the hospital and aged care sectors. J Safety Res. 2011;42(6):487-92.

46. Aschkenasy MT, Rothenhaus TC. Trauma and falls in the elderly. Emerg Med Clin North Am. 2006;24(2):413-32.

47. Siracuse JJ, Odell DD, Gondek SP, Odom SR, Kasper EM, Hauser CJ, et al. Health care and socioeconomic impact of falls in the elderly. Am J Surg. 2012;203(3):335-8.

48. Hartholt KA, van Beeck EF, Polinder S, van der Velde N, van Lieshout EM, Panneman MJ, et al. Societal consequences of falls in the older population: injuries, healthcare costs, and longterm reduced quality of life. J Trauma. 2011;71(3):748-53.

49. Coronado VG, Xu L, Basavaraju SV, McGuire LC, Wald MM, Faul $\mathrm{MD}$, et al. Surveillance for traumatic brain injury-related deaths-United States, 1997-2007. MMWR Surveill Summ. 2011;60(5):1-32.

50. Grundstrom AC, Guse CE, Layde PM. Risk factors for falls and fallrelated injuries in adults 85 years of age and older. Arch Gerontol Geriatr. 2012;54(3):421-8. 